\title{
KAJIAN KODE BAHASA, SASTRA DAN BUDAYA DALAM KUMPULAN CERPEN PILIHAN KOMPAS 2013 SEBAGAI PEMILIHAN BAHAN AJAR PROSA FIKSI PADA MAHASISWA PROGRAM STUDI PENDIDIKAN BAHASA, SASTRA INDONESIA DAN DAERAH FKIP UNPAS BANDUNG
}

\author{
Setiawan \\ Dosen PBSID FKIP Universitas Pasundan \\ Email: setiawan@unpas.ac.id
}

\begin{abstract}
Abstrak
Penelitian ini dimaksudkan untuk mengetahui karakteristik cerpen Kompas 2013 melalui pendeskripsian hasil analisis sistem kode dan pemananfaatan sebagai bahan ajar. Penelitian ini menggunakan metode deskriptif-analitis, artinya setiap data yang diperoleh dianalisis. Data kualitatif diperoleh dari hasil analisis terhadap karya sastra sesuai menurut teori telaah sastra. Berdasarkan hasil analisis terhadap kode bahasa, empat cerpen pilihan kompas mempunyai karakteristik kode bahasa yang berbeda satu sama lainnya. Kode sastra, tergambarkan pada ragam gaya bahasa yang dibuat pengarang. Kode budaya dalam empat cerpen ini memiliki unsur-unsur budaya seperti sistem kepercayaan, sistem kemasyarakat dan sistem mata pencaharian hidup. Nilai-nilai dalam empat cerpen terdiri atas nilai moral, nilai sosial dan nilai agama/religius. Data kuantitatifnya dilihat dari aspek hasil analisis mahasiswa dengan nilai tertinggi 90 dan nilai terendah 50. Selanjutnya, berdasarkan analisis kode bahasa, kode sastra dan kode budaya terhadap cerpen dan pedoman kriteria pemilihan bahan ajar, serta pemikiran dosen mata kuliah, maka cerpen pilihan kompas 2013, dapat diandalkan sebagai materi atau bahan ajar karena mengandung nilai-nilai berdasarkan hasil analisis.
\end{abstract}

Kata Kunci:Kode Bahasa, Kode Sastra, Kode Budaya, dan Bahan Ajar.

\begin{abstract}
This research is intended to know the characteristics of short stories Kompas 2013 through the descriptions of code analysis and utilization of the results as teaching materials. This research uses descriptive-analytical method, meaning that every data obtained is analyzed. Qualitative data obtained from the analysis of literary works according to the theory of literature review. Based on the results of the analysis of the language code, four short stories of compass choices have the characteristics of different language codes with each other. Literary code, depicted on the variety of styles made by the author. Cultural codes in these four short stories have cultural elements such as belief systems, community systems and living livelihood systems. Values in four short stories consist of moral values, social values and religious /religious values. Quantitative data seen from the aspect of student analysis results with the highest score of 90 and the lowest score 50. Furthermore, based on the analysis of language code, literary code and cultural code on the short story and the criteria of the selection of teaching materials, as well as the thought of lecturers, Reliable as a material or teaching material because it contains values based on the results of the analysis.
\end{abstract}

Keywords:Language Code, Literature Code, Culture Code, and Course Matter. 


\section{PENDAHULUAN}

Ilmu sastra saat ini menjadi ilmu yang mulai diminati, walaupun tetap belum dapat dikategorikan menjadi salah satu bidang ilmu yang menarik bagi peserta didik. Kondisi seperti ini bisa kita lihat dari berbagai sisi pendapat yang berkembang di tingkat mahasiswa. Ada yang memandang sastra hanya dalam ujaran orang lain, dan ada juga yang memahami dengan cara meneliti langsung beroleh pengalaman. Maka, untuk memperoleh ilmu sastra secara utuh kita harus mampu menyesuaikan dengan tujuan sastra seperti yang diungkapkan Rusyana (1982:6) bahwa sastra harus mempunyai tujuan beroleh pengalaman dan pengetahuan tentang sastra.

Beroleh pengalaman dan pengetahuan dalam sastra tidak bisa dilakukan sebagian saja, tetapi tujuan ini mempunyai tahapan-tahapan atau proses untuk mendapatkan pengalaman dan pengetahuan ini perlu dimiliki oleh setiap orang dengan melakukan apresiasi dan kajian teori agar tujuan pembelajaran sastra dapat tercapai.

Pendapat lain yang menguatkan tentang tujuan sastra yang baik yaitu bagi siapapun yang mengapresiasinya, karena ketika mengapresiasi sastra akan melibatkan tiga aspek sebagaimana diungkapkan Squire dan Taba seperti yang dikutip Aminuddin (2013:34) yaitu (1) aspek kognitif, (2) aspek emotif dan (3) aspek evaluatif. Tujuan-tujuan tersebut akan sangat bermanfaat bagi pembaca sastra atau peserta didik, apabila peserta didik mampu mempunyai variasi atau pendekatan dalam menginterpretasi sastra dengan baik.

Ada enam cara atau jenis interprestasi yang biasa digunakan dalam upaya membantu memahami teks karya sastra tulis seperti yang dikemukakan Luxemburg (1986:63) Pertama, penafsiran yang bertitik tolak dari pendapat, bahwa teks sendiri sudah jelas. Kedua, penafsiran yang berusaha untuk menyusun kembali arti historik. Ketiga, penafsiran hermeneutik baru yang terutama diwakili oleh Gadamer berusaha memperpadukan masa silam dan masa kini. Keempat, tafsiran-tafsiran yang dengan sadar disusun dengan bertitik tolak pada pandangannya sendiri mengenai sastra. Kelima, tafsiran-tafsiran yang bertitik pada suatu problematik tertentu. Keenam, tafsiran-tafsiran yang tidak langsung berusaha agar secara memadai sebuah teks diartikan, melainkan hanya ingin menunjukkan kemungkinan-kemungkinan yang tercantum dalam teks, sehingga pembaca sendiri dapat menafsirkan.

Pada perguruan tinggi khususnya program studi Pendidikan Bahasa, Sastra Indonesia setidaknya ada pembelajaran prosa fiksi yang mencakup novel, cerpen, hikayat dan karya fiksi lainnya. Di antara jenis prosa fiksi tersebut, maka minat baca mahasiswa sebagian besar pada cerpen. Dari minat mahasiswa nampaknya cerpen bisa dijadikan karya sastra yang disenangi oleh para mahasiswa karena dengan alasan teksnya yang tidak panjang dan bisa dibaca sekali duduk dengan tidak memerlukan waktu yang panjang.

Pada saat ini masih banyak kesulitan yang ditemukan pembaca dalam memahami cerpen. Hal itu disebabkan beragamnya sistem kode yang digunakan dalam karya sastra tersebut. Di sisi lain, banyak cerpen yang tidak sesuai secara budaya dengan kondisi budaya masyarakat kita. Hal ini bisa disebabkan latar belakang pengarang, keadaan pengarang dan budaya pengarang. Menurut Teeuw (1984:83) memahami konvensi budaya dalam karya sastra sering bersamaan dalam konvensi bahasa dalam karya sastra sehingga sulit untuk dipisahkan di antara keduanya, sehingga untuk memahami karya sastra perlu kiranya peserta didik atau siapapun 
(baca:pembaca) memahami kode bahasa, kode sastra dan kode budaya dalam karya sastra.

Penganalisisan tersebut bertolak dari asumsi yang dikemukakan Aminuddin (1995:55) pertama, karya sastra merupakan gejala komunikasi yang berkaitan dengan pengarang, wujud karya sastra sebagai sistem tanda, dan pembaca. Kedua, karya sastra merupakan salah satu bentuk penggunaan sistem lambang (system of sign) yang memiliki struktur dalam tata tingkat tertentu. Keti$g a$, karya sastra merupakan fakta yang harus direkonstruksi pembaca sejalan dengan dunia pengalaman dan pengetahuan yang dimilikinya.

Landasan di atas, pada penelitian ini peneliti mencoba menggunakan kajian semiotik sebagai suatu pendekatan ilmiah dalam memahami karya sastra dari aspek kode bahasa, kode sastra dan kode budaya sebagai usaha untuk pembacaan suatu tanda dan lambang yang diberikan pengarang kepada pembaca. Karena menurut Seger (1978:18) pertanyaan pertama yang harus dihadapi pembaca dalam situasi pembacaan yang sebenarnya, bukan dengan cara manakah teks tersebut harus 'dibongkar', tetapi dalam bahasa atau kode yang mana suatu teks 'disusun'.

Menurut Barthes (2007:223) yang menguatkan pendapat Seger di atas bahwa problema yang dihadapi bukan yang berhubungan dengan usaha mengintrospeksikan memeriksa motif-motif yang ada pada si narator bukan pula menginstrospeksi efek-efek yang dilakukan oleh narasi atas pembaca. Tetapi problemanya adalah tentang bagaimana mendeskripsikan sistem kode yang dilewatiditaati si narator dan si pembaca sehingga bisa menjadi signifie-signifie di sepanjang cerita itu sendiri.

Langkah ini sebagai tahapan evaluasi karya sastra sebagaimana diungkapkan Seger (1978:88) bahwa analisis proses evaluasi sastra dapat dilakukan dengan beberapa cara, di antaranya: (1) analisis terhadap struktur dan kode tekstual; (2) ana-lisis terhadap horizon harapan pembaca; (3) analisis terhadap hubungan timbal balik antara 1 dan 2 . Nampaknya sangat penting kajian ini dilakukan agar karya sastra yang diajarkan mampu menambahkan wacana positif bagi peserta didik dan umumnya bagi bangsa. Langkah itu perlu ditempuh dengan suatu analisis dan penelitian.

\section{KAJIAN TEORETIS Kode}

Menurut Luxemburg (1986:92) bahwa yang disebut dengan kode adalah tanda-tanda yang merupakan sebuah sistem. Hal ini diperkuat dengan apa yang dikatakan Seger (1978:9) bahwa kode merupakan sistem tanda mana pun yang dengan persetujuan sebelumnya antara sumber dan sasaran yang digunakan untuk menggambarkan dan membawakan situasi.

Dua pernyataan ini menjelaskan bahwa setiap tanda dalam cerita yang berfungsi untuk menggambarkan situasi penceritaan khususnya yang mendukung dalam tema penceritaan adalah sebuah bentuk kode yang membangun cerita tersebut.

Di sisi lain ada dua arti untuk memahami istilah kode sebagaimana yang diungkapkan Berger (2010:205) yaitu, pertama, kode menunjukkan bentuk status yang sistematis, aturan-aturan dan sebagainya, seperti kode Napoleon, kode Hamurabi. Kedua, arti kode menyangkut suatu ide yang rahasia, seperangkat bentuk, huruf atau simbol yang mengaburkan arti, tetapi yang dapat dipecahkan bila Anda mengetahui pokok penyusunan dari kode tersebut.

Dari pendapat di atas dapat diambil pemahaman bahwa yang disebut dengan kode adalah sekumpulan tandatanda dalam sebuah teks ataupun kon- 
teks yang perlu dipahami dengan menguasai pokok-pokok kode itu dan segala bentuk lambang, huruf, kata atau tanda tersendiri. Dalam menganalisis karya sastra dengan sistem kode yang menjadi alat pembedahnya, maka pembaca tidak bisa lepas dari ketiga sistem kode penting yaitu kode bahasa, kode sastra dan kode budaya.

\section{Kode Bahasa}

Menurut Luxemburg (1986:92) bahwa kode bahasa itu dicantumkan dalam kamus-kamus dan tata bahasa. Pendapat lain menguatkan perihal langkah untuk memahami kode bahasa yang dijelaskan Teeuw (1991:19) bahwa kode bahasa bisa dipahami ketika kita memaknai bahasa sehari-hari yang tidak dimilikinya: urutan kata, pemakaian morfem bahasa, irama, dan seterusnya.

Penjelasan kode bahasa tersebut menjadi landasan teori dalam upaya menganalisis kode bahasa pada aspek bahasa yang sulit/asing dipahami pembaca dan untuk memudahkannya, maka kata tersebut diklasifikasikan dalam bentuk jenis kata seperti kata benda, kata kerja, kata sifat kata bilangan dan jenis kata lainnya.

Pengkajian ini menguatkan pemahaman bahwa kajian kode bahasa menjadi sangat penting dalam memahami teks-teks sastra secara konteks kebahasaan dan sebagai media utama dalam karya sastra.

\section{Kode Sastra}

Menurut Miller seperti yang dikutip oleh Seger (1978:18) kode sastra dapat dirumuskan sebagai suatu sistem tanda-tanda verbal yang dipergunakan untuk menggambarkan atau menyampaikan informasi. Teeuw mengungkapkan (1991:14), sesungguhnya kode sastra itu tidak mudah dibedakan dengan kode budaya, meskipun begitu, pada prinsipnya keduanya tetap harus dibedakan dalam kegiatan membaca dan memahami teks sastra.

Kristeva seperti yang dikutip oleh Zaimar (2014:97) menegaskan bahwa kode sastra pada hakikatnya tidak terbatas pada satu bahasa saja, kode itu dapat melampaui berbagai bahasa sehingga menjadi tak terbatas.

Dalam sastra sebenarnya bisa terjadi pemakaian kode yang sama antara pengarang dan pembaca. Bukan hanya ada kode sastra secara khusus tetapi ada Istilah lain yang dipakai dalam teori Amanat Roland Barthes seperti kode aksian yang merupakan prinsip bahwa di dalam tuangan bahasa secara tulis perbuatan-perbuatan itu harus disusun secara linear. Berikutnya Kode proaretik atau kode tindakan/lakuan dianggapnya sebagai perlengkapan utama teks yang dibaca orang; antara lain, semua teks yang bersifat naratif.

Ada yang perlu diperhatikan pembaca manakala akan membahas atau berhadapan dengan karya sastra yaitu ragam atau aspek kode sastra seperti yang diungkapkan Teeuw (1983:17) sebagai berikut.

1) Perlu saya ulang bahwa kode sastra tidak lepas dari kode bahasa. Bahasa dengan segala sesuatunya adalah sesuatu yang diberikan, yang tidak dapat dihindari, tetapi yang harus dimanfaatkan sebaik mungkin.

2) Tetapi walaupun pada prinsipnya setiap pengarang sastra setuju bahwa bahasa sehari-sehari harus dihilangkan kelunturannya, biasanya mereka lebih cenderung menganggap bahasa sebagai kawan daripada lawan. Bentuknya yang spesifik tidak dihiraukan oleh pemakai dan pendengarnya, asal cocok dengan maksudnya, asal sesuai dengan kode bahasa dan tidak menimbulkan salah paham, dan sering sekali dalam pengutaraan bahasa sehari-hari ter- 
dapat yang berlebih-lebihan, yang redundan. Ada dua prinsip universal utama yang berfungsi dalam kode bahasa sastra ini: prinsip ekuivalensi atau kesepadanan; dan prinsip deviasi atau penyimpangan.

3) Tetapi sistem konvensi sastra tidak hanya ditentukan oleh kemungkinan, kelonggaran dan pembatasan yang diberikan oleh sistem bahasa itu sendiri.

4) ...karya sastra merupakan dunia yang otonom, yang tidak terikat kepada dunia nyata, kecuali melalui makna unsur bahasa yang dipakai di dalamnya.

5) ...bahwa dunia rekaan yang wajib saya bangun berdasarkan data bahasa karya sastra itu mempunyai relevansi dan signifikasi.

6) ...dengan kata lain, sebuah karya sastra harus merupakan sebuah keseluruhan yang mempunyai sebuah struktur yang konsisten dan koheren, di mana setiap bagian merupakan unsur-unsur esensial dan menempati tempat yang layak dan wajib.

Ragam atau aspek kode sastra tersebut menjadi landasan kuat bahwa pengkajian sastra tidak cukup dengan pengkajian kode bahasa tetapi memerlukan pengetahuan dan pemahaman yang lebih tentang sistem konvensi sastra yang didasarkan pada aturan konvensional teori dan sejarah sastra.

Dalam penelitian ini penulis mencoba akan menjabarkan ragam kode sastra dengan membatasi pada ranah bahasa sastra atau gaya bahasa yang digunakan sebagai bentuk penyimpangan atau bisa disebut dengan deviasi.

\section{Kode Budaya}

Tahapan ketiga dalam analisis karya sastra dalam upaya mengkaji mengapresiasi karya sastra adalah dengan memahami kode budaya yang menjadi bagian dalam penceritaan suatu karya sastra. Kode budaya ini bisa dipahami, manakala kita sudah mengetahui teori tentang budaya atau kebudayaan dari unsur-unsur dan nilai-nilainya.

Berger (2010:205) mengatakan bahwa kode budaya (cultur code) merupakan struktur rahasia yang membentuk perilaku kita... atau setidaknya mempengaruhi kita. Kode budaya adalah pemahaman terhadap latar kehidupan, konteks, dan sistem sosial budaya. Sementara Barthes seperti yang dikutip Santosa (1993:33) menjelaskan bahwa kode budaya atau acuan merupakan peranan metalingual. Latar sosial budaya yang terdapat dalam sebuah cerita rekaan memungkinkan adanya suatu kesinambungan dari budaya seluruhnya.

Kode gnomic atau kode cultural merupakan acuan teks ke benda-benda yang sudah diketahui dan dikodifikasi oleh budaya. Kode ini merupakan peranan metalingual. Hal ini terlihat faalnya bila yang terjadi dalam susastra itu dihubungkan dengan realitas budaya. Karena cerita rekaan memungkinkan adanya suatu kesinambungan dari budaya sebelumnya.

Menurut Chapman dalam Berger (2010:26), kelahiran karya sastra diprakondisikan oleh kehidupan sosial budaya pengarangnya. Karena itu, sikap dan pandangan pengarang dalam karyanya mencerminkan kehidupan sosial budaya masyarakatnya.

Kaitan budaya dan sastra memang dua sisi yang tidak bisa dipisahkan dalam hal ini. Ratna (2010:415) mengemukakan bahwa yang memaknai sastra itu hanya masyarakatlah. Sejalan dengan pernyataan tersebut Teeuw (1984:83) bahwa untuk memahami suatu roman kita harus memahami konvensi sosiobudaya setempat.

Alasan yang sama diungkapkan Pradopo (2001:55-56), menyatakan bahwa karya sastra sebagai tanda terikat 
pada konvensi masyarakatnya, karena merupakan cermin realitas budaya masyarakat yang menjadi modelnya.

Seorang semiolog asal Prancis yaitu Roland Barthes berpendapat bahwa ada jenis-jenis kode yang paling penting yaitu kode sosial, kode estetik dan kode logis.

Ketiga kode tersebut cenderung berubah-ubah (dinamis) berbeda dengan kode ilmiah yang cenderung statis. Hakikatnya ketiga kode tersebut ialah penemuan manusia dan bagian dari produk kultur (budaya).

Beberapa persamaan dan perbedaan pada pendapat tersebut bahwa karya sastra memang tidak bisa terlepas dengan pengarang sebagai bagian dari pencipta, penikmat dan penjaga budaya. Maka penganalisisan kode budaya harus dikembalikan kepada unsur dan sistem budaya setempat sesuai dengan yang diceritakan pengarangnya.

\section{Cerpen}

Secara etimologis bahwa 'cerpen' suatu akronim dari cerita pendek yang diambil dari istilah bahasa Inggris yaitu short story atau diterjemahkan ke dalam bahasa Indonesia tepatnya menggunakan istilah cerita pendek atau cerpen. Beberapa pendapat di bawah ini akan menjelaskan bahwa pendefinisian cerita pendek sudah lama dikenal di kalangan ahli sastra di berbagai negara.

Menurut Sedgwick seperti yang dikutip Tarigan (2011:179) bahwa cerpen adalah penyajian suatu keadaan tersendiri atau suatu kelompok keadaan yang memberikan kesan yang tunggal pada jiwa pembaca. Dikatakan tunggal karena titik permasalahan yang diberikan dalam sebuah cerpen tidak banyak penyimpangan atau digresi penceritaan, sehingga pembaca bisa secara langsung memahami maksud dari suatu cerpen.

Pendapat Poe seperti yang dikutip oleh Nurgiyantoro (2010:10) cerpen adalah sebuah cerita yang dibaca dalam sekali duduk, kira-kira berkisar antara setengah sampai dua jam. Pendapat Poe lebih menitik beratkan cerpen dalam hal waktu pembacaan karena dilihat dari segi berapa lamanya seseorang dalam membaca sebuah cerpen. Bentuk cerpen ini masuk dalam karangan prosa fiksi. Isi dari cerpen ini sama halnya dengan novel. Hanya saja cerpen memiliki plot yang tunggal tidak ada penyimpanganpenyimpangan dalam alur penceritaan seperti halnya novel.

Beberapa pendapat tersebut kiranya dapat diambil kesimpulan bahwa yang disebut dengan cerpen adalah karya sastra naratif yang bersifat fiksi dengan plot tunggal dan bisa dibaca sekali duduk, sehingga sepanjangpanjangnya cerpen tidak akan melebihi novel.

\section{Bahan Ajar}

Majid (2009:173) berpendapat bahwa yang disebut dengan bahan ajar adalah segala bentuk bahan yang digunakan untuk membantu guru/instruktur dalam melaksanakan kegiatan belajar mengajar.

Pendapat lain telah diungkapkan Iskandarwassid (2011:171) bahwa bahan ajar merupakan seperangkat informasi yang harus diserap peserta didik melalui pembelajaran yang menyenangkan.

Dapat ditarik kesimpulan bahwa yang disebut dengan bahan ajar adalah segala bentuk yang disusun untuk membantu pengajar dalam menyampaikan informasi atau kegiatan pembelajaran kepada siswa.

\section{METODE PENELITIAN}

Secara terminologis, metode penelitian dapat didefinisikan sebagai cara ilmiah untuk mendapatkan data yang valid dengan tujuan dapat ditemukan, dikembangkan, dan dibuktikan, suatu pengetahuan tertentu sehingga pada 
gilirannya dapat digunakan untuk memahami, memecahkan, dan mengantisipasi masalah dalam bidang pendidikan (Sugiyono, 2010:6).

Jenis penelitian yang digunakan adalah penelitian kualitatif. Penelitian kualitatif yang berpendapat bahwa metode penelitian kualitatif berlandaskan pada filsafat postpositivisme, digunakan untuk meneliti pada kondisi obyek yang alamiah.

Peneliti menggunakan metode deskriptif. Penelitian ini bersifat mendeskripsikan, memaparkan dan menganalisis data. Data yang diperoleh yaitu dari analisis kode bahasa, sastra dan budaya pada cerpen.

Oleh karena itu penelitian ini bersifat deskriptif, maka dalam menganalisis dan mengolah data penulis bersandarkan pada suatu teori agar dapat menganalisis. Penulis bertindak sebagai peran utama dalam penelitian ini.

Metode yang digunakan dalam penelitian ini adalah metode deskriptif analitik. Metode penelitian ini digunakan untuk menganalisis sistem kode yang terdapat dalam cerpen pilihan Kompas 2013. Sumber data yang sesuai dengan masalah penelitian yaitu empat teks cerpen pilihan Kompas 2013. Sumber data yang akan diuraikan sebagai karya sastra berjenis cerpen pilihan Kompas 2013 sebagai representatif dari karya sastra berbentuk prosa fiksi dari genre sastra Indonesia baru yang banyak dibaca khalayak banyak.

\section{HASIL DAN PEMABAHASAN Kode Bahasa}

Berdasarkan kajian/analisis yang telah dilakukan, maka diperoleh data bahwa kode Bahasa yang terdapat pada empat cerpen adalah sebagai berikut: cerpen pertama yaitu cerpen Lelaki Ragi dan Perempuan Santan masih dipengaruhi oleh bahasa minang dan melayu. Jumlah kosa kata yang menjadi kode bahasa berjumlah 12 kata yang termasuk jenis bahasa nomina seperti kata sipulut, penakik, balam, serambi, hantaran, kenduri, semang, tarikh. Kode bahasa verba seperti kata diperam, mendedahkan, membelot. Kode bahasa ajektif yaitu kata mencong. Kata ini diklasifikasikan seperti berikut: Kode bahasa nomina/ben-da 8 kata, kode bahasa verba/kerja 3 kata dan kode bahasa ajektif/sifat 1 kata.

Kode bahasa yang digunakan dalam cerpen kedua yaitu cerpen Ulat Bulu \& Syekh Daun Jati ada yang menggunakan kode bahasa daerah sebagai tanda penguasaan penulisnya dalam penceritaan seperti kata ora sare pada paragraf 10. Cerpen kedua memiliki jumlah kosa kata yang menjadi kode bahasa berjumlah 10 kata yaitu kode bahasa nomina seperti kata pageblug, belarak, kisanak, perigi. Kode bahasa verba seperti, berkerugetan, menebahkan, bergemertak, kelebat. Kode bahasa ajektif yaitu kata lempung. Kata-kata ini diklasifikasikan seperti berikut: Kode bahasa nomina/benda 4 kata, kode bahasa verba/kerja 4 kata dan kode bahasa ajektif/sifat 1 kata.

Kode Bahasa cerpen ketiga yaitu cerpen Kota Tanpa Kata dan Air Mata ditandai dengan adanya kata dari berbagai bahasa yang digunakan sebagai tanda oleh penulis untuk mendukung ide penceritaan yang ingin disampaikan seperti kata hexagon dan Paving Block. Pada cerpen ketiga memiliki jumlah kosa kata yang menjadi kode bahasa berjumlah 13 kata yaitu kode bahasa nomina seperti kata kepul, peron, gelak, peluh, porselin, komoditas, ufuk. Kode bahasa verba seperti menyeruak, memintal, menyengapku. Kode bahasa ajektif seperti kata getas, parau dan riuh. Katakata ini diklasifikasikan seperti berikut: kode bahasa nomina/benda 7 kata, kode bahasa verba/kerja 3 kata dan kode bahasa ajektif/sifat 3 kata. Jumlah ini 
lebih banyak dari pada cerpen yang lainnya.

Kode bahasa cerpen keempat ditandai dengan penggunaan bahasa Indonesia dengan kosa kata yang jarang digunakan seperti beludak, tube-tube dan terhuyung-huyung. Cerpen keempat lebih sedikit daripada cerpen ketiga. Namun masih lebih banyak daripada cerpen kesatu dan kedua. Pada cerpen keempat yaitu cerpen Pada Jam 3 Dini Hari memiliki jumlah kosa kata yang menjadi kode bahasa berjumlah 11 kata, yaitu kode bahasa nomina seperti kata gazebo, sulur-sulur, beludak, antah berantah, kefanaan, kontur, tube-tube. Kode bahasa verba seperti kata terhuyung-huyung. Kode bahasa ajektif seperti kata kalut dan sephia. Kode bahasa numeralia seperti kata seantero. Katakata ini diklasifikasikan seperti berikut: kata nomina/benda 7 kata, kata verba/kerja 1 kata, kata ajektif/sifat 2 kata dan kode bahasa numerelia/bilangan 1 kata.

\section{Kode Sastra}

Kode sastra yang terdapat dalam dalam empat cerpen tersebut bisa terlihat pada penggunaan gaya bahasa perulangan, perbandingan, pertautan, dan pertentangan. Formulasi yang dibuat masing-masing pengarang mempunyai persamaan dan perbedaan pada cerpen yang ditulisnya.

Cerpen pertama yaitu cerpen Lelaki Ragi dan Perempuan Santan, pengarang menggunakan kode sastra seperti kode sastra defersonifikasi, sinekdoke, erotesis, metafora, ellipsis, personifikasi, anabasis, prolepsis, simi$l e$, dan oksimoron. Cerpen kedua yaitu cerpen Ulat Bulu \& Syekh Daun Jati menggunakan kode sastra berjumlah 9 kode sastra seperti mesodilopsis, sinekdoke, erotesis, personifikasi, alusi, epitet, alegori dan innuendo. Cerpen ketiga yaitu cerpen Kota Tanpa Kata dan Air
Mata mengandung 9 kode sastra seperti kode sastra simile, metafora, personifykasi, hiperbola, ellipsis, asindenton, defersonifikasi, oksimoron dan erotesis. Cerpen keempat yaitu cerpen Pada Jam 3 Dini Hari mengandung 8 kode sastra seperti kode sastra tautology, perumpamaan, alusi, katabasis, erotesis, hiperbola, sinekdoke dan personifikasi.

\section{Kode Budaya}

Kode Budaya yang terdapat dalam empat cerpen tergambarkan dalam wujud kode budaya unsur-unsur budaya seperti kode kepercayaan, kode kemasyarakatan dan kode ekonomi. Nilainilai budaya adalah seperti nilai moral, nilai sosial dan nilai agama.

Berdasarkan pertimbangan analisis kode bahasa, kode sastra dan kode budaya, keempat cerpen Kompas 2013 layak dijadikan bahan ajar pada mata kuliah Apresiasi dan kajian Prosa Fiksi Indonesia.

\section{Bahan Ajar}

Jenis bahan ajar yang digunakan dalam pembelajaran menganalisis kode bahasa, kode sastra dan kode budaya cerpen pilihan Kompas 2013 ialah lembar kerja mahasiswa. Lembar kerja mahasiswa tersebut disusun berdasarkan tahap-tahap perumusan tujuan instruksional, analisis intruksional, merumuskan capaian pembelajaran dan indikator capaian pembelajaran, menyusun Rencana Pembelajaran Semester (RPS). Lembar Kerja Mahasiswa (LKM).

\section{SIMPULAN}

Berkenaan dengan analisis yang telah diperoleh di atas, dalam hal ini disimpulkan bahwa keempat cerpen yaitu cerpen cerpen Lelaki Ragi dan Perempuan Santan, Ulat Bulu \& Syekh Daun Jati, Kota Tanpa Kata dan Air Mata, dan Pada Jam 3 Dini Hari mempunyai penggunaan kode bahasa yang 
beragam dengan campuran bahasa Indonesia baku dan bahasa daerah, kode sastra yang beragam dari berbagai jenis gaya bahasa yang dijadikan sebagai ciri kode sastra yang digunakan masingmasing pengarang dan adanya kode budaya yang variatif dengan mengangkat kode budaya lokal sebagai warna penceritaan dalam cerpennya masingmasing.

\section{DAFTAR PUSTAKA}

Aminuddin. 2013. Pengantar apresiasi karya sastra. Bandung: Sinar Baru Algesindo.

Barthes, Roland. 2007. Petualangan semiologi. Yogyakarta: Pustaka Pelajar.

Berger, Arthur Asa. 2010. Pengantar semiotika tanda-tanda kebudayaan. Yogyakarta: Tiara Wacana.

Iskandarwassid, 2011. Strategi pembelajaran bahasa. Bandung: Rosda Karya.

Luxemburg, Jan Van dkk. 1986. Pengantar ilmu sastra. Jakarta: PT. Gramedia.

Majid, Abdul. 2009. Perencanaan pembelajaran. Bandung: Rosda Karya.

Nurgiyantoro, Burhan. 2010. Teori pengkajian fiksi. Yogyakarta: Gadjah Mada University Press.

Pradopo. Rachmat Djoko. 2011. Beberapa teori sastra, metode kritik dan penerapannya. Yogyakarta: Pustaka Pelajar.

Ratna, Nyoman K. 2010. Sastra dan cultural studies representasi fiksi dan fakta. Yogyakarta: Pustaka pelajar

Rusyana, Yus. 1982. Metode pengajaran sastra. Bandung: Gunung Larang.

Santosa, Puji. 1993. Ancangan semiotika dan pengkajian susastra. Bandung: Angkasa.
Segers, Rien T. 2000. Evaluasi teks sastra. Yogyakarta: Adicita.

Sugiono. 2010. Metode penelitian pendidikan pendekatan kuantitatif, kualitatif, dan $R \& D$. Bandung: Alfabeta.

Tarigan, Henry Guntur. 2011. Prinsipprinsip dasar sastra. Bandung: Angkasa.

Teeuw, Andreas. 1983. Membaca dan menilai sastra. Jakarta: PT. Gramedia.

Teeuw, Andreas. 1984. Sastera dan ilmu sastera. Bandung: Pustaka Jaya. 